\title{
Maximizing Educator Enhancement: Aligned Seminar And Online Professional Development
}

\author{
Steven Shaha, Ph.D., DBA, University of Utah, USA \\ Kelly Glassett, Ph.D., University of Utah, USA \\ Aimee Copas, Ph.D., North Dakota Council of Educational Leaders, USA \\ T. Lisa Huddleston, Principal, Livingston County Middle School, USA
}

\begin{abstract}
Professional development and learning has a long history in seminar-like models, as well as in the more educatorpersonal delivery approaches. The question is whether an intentionally coordinated, integrated combination of the two PDL approaches will have best impacts for educators as quantified in improved student performance. Contrasts between baseline and Post-Program performance levels showed 19\% gains in Reading and 24\% gains in Math, significantly beyond expectation. Analyses for Title 1 schools showed significant shrinkage of performance gaps with contrasted non-Title 1 schools. These gains outpaced those found for either PDL approach alone, indicating that educational leaders will be wise to undertake implementation of intentionally aligned and coordinated approaches combining PDL Seminars with online, on-demand PDL.
\end{abstract}

Keywords: Professional Development; Professional Learning; Educational Benefits; Outcomes and Results; Student Advancement/Achievement

\section{BACKGROUND \& INTRODUCTION}

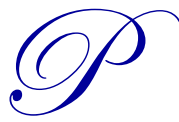

rofessional development and professional learning (PDL) is a long-standing approach to providing value to teachers and educators (c.f. Avalos, 2011; Borko, 2004; Villegas-Reimers, 2003; Wayne, et.al, 2008; Wilson \& Berne, 1999). The purpose of PDL has appropriately been to help educators feel more effective, refine and progress their skills and capabilities as educators, and have a greater impact on the students they have chosen to serve. Quantified proof of PDL impact is one challenge for educational leaders whose responsibilities include spending precious educational funds. Expenditures fail to be investments unless the higher aims of education are achieved.

Most PDL offerings still lack any substantive or rigorous evidence of verified favorable educational impacts (c.f. Boyle, et.al, 2004; Garet, et.al, 2001). Marketing materials and testimonials alone are inadequate as a rationale base for the expenditure of limited funds whose purpose should be enhancing educator impacts on students - decision rationale must be based on more than participant satisfaction alone (c.f. Avalos, 2011; Borko, 2004; VillegasReimers, 2003; Wilson \& Berne, 1999). The most rigorous research metrics for PDL evaluation should focus on teacher impact on student performance (c.f. Borko, 2004; Garet, et.al. 2001; Wayne, et.al. 2008). Educator PDL approaches with rigorous proof of favorable impacts on student gains should be preferred over those lacking such substantive cost justification.

Educator PDL approaches have generally evolved in two directions, including PDL group seminars and PDL offerings more focused on personal participation which have recently matured into Internet-delivered PDL. But for research purposes, we choose to focus on the seminars and Internet-delivered approaches for our quasi-experimental undertakings, since each can be readily and rigorously studied through pre-versus-post or have-versus-have-not designs.

A brief review of research for each PDL direction is appropriate and helpful, and raises crucial questions. 


\section{SEMINAR-BASED PROFESSIONAL DEVELOPMENT}

Beyond college-based training and experience, seminars have been a traditional basis for defining and delivering professional development for educators. Teachers customarily participate in conference-like settings and are exposed to concepts and methods of teaching designed to refine or endow a host of educator-relevant skills. While some seminar PDLs are conducted in calendar months when schools are not in session, many seminars require that teachers leave the classroom to participate, requiring replacement teachers or other student management approaches, all costing more funds, loss of classroom time with the designated day-to-day teacher, and turmoil (c.f. Abdal-Haqq, 1996).

Many studies have quantified impacts of PDL-focused seminars for educators (Borko, 2004; Koehler, Mishra \& Yahya, 2007; Wayne, et.al. 2008; Zeichner, 2003). Very few quantify any impact on student performance, traditionally focusing more on measuring participant satisfaction and testimonials of value. As a result, it appears that PDL choices made by educational leaders are dependent upon marketing-related concepts, reflections and promises, and not on any substantiated or rigorously quantified impact teachers had on their students. We consider that an unfortunately inadequate situation (c.f. Villegas-Reimers, 2003).

\section{ONLINE, ON-DEMAND PROFESSIONAL DEVELOPMENT}

With the advent and expansion of technology, approaches to PDL have evolved in the past 20-30 years toward greater use of options undertaken individually by educators, including video, computer-based options, and most recently Internet-delivered options (c.f. Schrum, 1995). The most advanced PDL offerings now leverage the ubiquity of the Internet to expand to online, on-demand capability offerings accessible whenever and wherever most convenient for educator enhancement (c.f. Dede, 2006; Schlager \& Fusco 2003; Schrum, 1995; Wayne, et.al., 2008). Most of those advanced offerings are achieved through Internet-delivered video (c.f. Borko, et.al, 2008; Koc, Peker,

\& Osmanoglu, 2009). The cost effectiveness of Internet-delivered PDL in comparison to seminars has been part of its success and the expansion of commercial providers and offerings, resolving replacement-teachers expenses and other costs associated with participative seminar approaches (c.f. Abdal-Haqq, 1996; Garet, et.al. 2001; Zhang, et.al. 2011).

Further, recent rigorous studies have substantiated the impact of online, on-demand PDL approaches, at least for one of the market offerings (c.f. Shaha \& Ellsworth, 2013, 2014a; Shaha, Glassett \& Copas 2015a, 2015b; Shaha, Glassett \& Ellsworth, 2015). In these studies, the percentage of students classified as Proficient and Advanced in Math and Reading increased 18\% more year-over-year in online PDL schools then for their own respective (i.e. matched) non-participating districts. And teachers experienced those advantages after the first year of the online, on-demand PDL use. Similar study findings for the same Internet-delivered PDL were quantified for Title 1 schools, which experienced $4.6 \%$ and $7.3 \%$ more students classified as Proficient and Advanced year-over-year for Reading and Math, respectively, versus the matched Title 1 control group which was either flat $(0.1 \%$ more $)$ or suffered performance losses (-5.9\%) for the same year-over-year contrasts (Shaha \& Ellsworth, 2014b; Shaha, et.al., 2015).

\section{SUMMARY AND OBJECTIVES}

With the impact data so substantive and clear, PDL decisions can and should be driven by a focus on increasing the impact educators have on their students. Clearly the impact of the Internet-enabled online, on-demand PDL for educators is established, as well as the focus generating and foundation-setting impact of seminars is legitimate. However, with both seminars and online approaches shown to have favorable impacts in general, what educators need is a proven approach combining the best of both worlds (c.f. Shaha \& Ellsworth, 2014a). Yet a review of the literature, however, did not lead to any research with findings regarding PDL offerings reflecting the coordinated, combined strengths of both approaches.

The question yet to be answered is whether a combination of the two approaches can be shown with data to be effective, and potentially even more impactful than what either approach has achieved separately. For decision makers, can the cost-effectiveness, convenience, ready-access and proven impactfulness of Internet-delivered PDL 
achieve even greater efficacy when integrated with an aligned PDL seminar? Further, would any potential benefits be generalizable to Title 1 school students?

\section{METHOD}

Combined data from nine previous studies of educational institutions were included in a meta-analysis of impact. Each study reflected inclusion categorizable as a uniform integrated PDL Program (hereafter, PDL Program), including both the same PDL Seminar throughout (i.e. Learning Framework ${ }^{\circledR}$, Schools Improvement Network, Salt Lake City), integrated with the same online, on-demand, Internet-delivered PDL for teachers (PD $360 \AA$, School Improvement Network, Salt Lake City). Analyses only included schools for which the two PDL approaches were intentionally implemented as an integrated, aligned, and coordinated undertaking. All data analyzed were included at the collective school level in order to ensure anonymity for teachers and students.

The sample included 52 total schools in seven districts within five of the states, with 39 elementary schools (75\%), three middle schools $(6 \%)$, and 10 high schools $(19 \%)$. Schools collectively represented geographic diversity from west to east, and north to south, as well as urban to rural, reflecting an estimated 1,400+ teacher and 26,000+ students. The sample represented a nearly average American ethnic mix (see Table 1; Aud, et al, 2010; Lee, 2002). The designation of "Title 1" for any school was preserved from a previous study for analysis of that group of schools separately (c.f. Shaha, et.al., 2015), which in this data set included 14 schools in four districts within four of the five states in the original data set.

Table 1. Cumulative Ethnic Mix in the Sample

\begin{tabular}{lc}
\hline & Sample \\
\hline White & $50.1 \%$ \\
Hispanic & $19.1 \%$ \\
Black - African American & $17.1 \%$ \\
Asian / Pac Islander & $8.2 \%$ \\
Native American & $1.1 \%$ \\
Multi Ethnicity & $4.4 \%$ \\
\hline Total & $100 \%$ \\
\hline
\end{tabular}

The study design reflected a quasi-experimental approach (Cook \& Campbell, 1979) wherein performance of naturalistically occurring classroom groups (i.e. school aggregates) were contrasted for three successive school years in a 3-year model. All data included in the meta-analysis were shifted such that years aligned to ensure analogous starting and ending parameters. Thus while specific calendar years for data varied between schools due to respective implementation schedules, all occurred between 2008 and 2013, with the same 3-year model applied uniformly. Within the 3-successive-year design:

- Pre-Year 1 data reflected mean student reading and mathematics performance school-wide for each school two full academic years before implementation.

- Pre-Year 2 data reflected performance data for the academic year closing immediately prior to the aligned, coordinated PDL implementation. Comparison of Pre-year 1 versus 2 quantified probable change rates in student performance without either the online, on-demand PDL or the Seminar.

- Post data reflected the year-end performance for the academic year of the combined PDL intervention.

Student performance was the metric for program impact evaluation. To adjust for different student performance instruments (i.e. standardized tests) between states, student performance for all analyses was defined as the sum of the percentages of students rated either proficient or advanced on their respective standardized student performance tests, for reading and mathematics (thus entitled despite varying labels). This approach also ensured generalizability (Shaha, Glassett \& Copas, 2015; Shaha, Glassett \& Ellsworth, 2015). Importantly, no changes in testing instrumentation occurred within any included states or districts for the three consecutive years of data. Student performance data were gathered from publically available web sources for the three consecutive school years.

Year-to-year percent change - gain or loss from start to end for each year - was used as the main measure for statistical analysis and interpretation, thus standardizing the basis of analysis regardless of either the calendar-year 
or absolute start or end points for any element within the sample. For analyses referring to Title 1 schools, the yearover-year change in percent of student classified as proficient or advanced was maintained and computed for an additional 14 Title 1 schools within the same states. However, the more relevant analyses focused on evaluating any change in the gap in student performance when contrasted with non-Title 1 schools (c.f. Aud, et al, 2010; Lee, 2002).

Percent change for reading and mathematics were computed as net change divided by performance for the earlier of the two years contrasted: e.g. (Year $2-$ Year 1)/ Year 1. Effect size was then computed and reported as the percent change Pre-Year 2 to Post, divided by the percent change for the previous periods, as well as by Cohen's $f^{2}$ (Cohen, 1992). Significance for percent change was determined by the t-Test for proportions (Rice, 2006). All analyses were conducted using SPSS version 17.0 or higher (PASW Statistics, SPSS, 2009, with SAS for confirmatory purposes when results were close to $\mathrm{p}<0.05)$. Minimum level of statistical significance was determined a priori at $\mathrm{p}<0.05$.

\section{RESULTS}

Contrasting Pre-Year 1 and Pre-Year 2 reflected favorable changes of 1.9\% and 1.7\% year-over-year for Reading and Math, respectively (see Table 2 and Figure 1). These growth rates reflect the pre-implementation rates, and thus provide a baseline from which to assess the program impact (Pre-Year 2 versus Post). Neither growth rate was statistically significant for any given school when analyzed alone, hence the designation of "not statistically significant" indicated within the table and illustrated in the figure. When the full collective sample size is reflected in cumulative analyses, then the percentages were significantly different from zero.

Table 2. Year-over-Year changes in Student Performance with and without the Integrated Program

\begin{tabular}{l|c|c|c|c|c|c|c}
\hline & \multicolumn{4}{|c|}{ Baselines } & \multicolumn{3}{c}{ Program Impacts } \\
\hline & Pre-Year 1 & Pre-Year 2 & $\begin{array}{c}\text { Year-over-Year } \\
\text { Performance Change }\end{array}$ & $\begin{array}{c}\text { Normal } \\
\text { Growth }\end{array}$ & $\begin{array}{c}\text { Post } \\
\text { Program }\end{array}$ & $\begin{array}{c}\text { Year-over-Year } \\
\text { Performance Change }\end{array}$ & $\begin{array}{c}\text { Program-enabled } \\
\text { Growth Rate }\end{array}$ \\
\hline Reading & $48.2 \%$ & $49.1 \%$ & $0.9 \% \dagger$ & $1.9 \%+$ & $58.9 \%$ & $9.8 \% * *$ & $19.96 \% * *$ \\
\hline Math & $45.9 \%$ & $46.7 \%$ & $0.8 \% \dagger$ & $1.7 \%+$ & $58.1 \%$ & $11.4 \% * *$ & $24.41 \% * *$ \\
\hline
\end{tabular}

$\dagger$ - Not statistically significant

** - Statistically significant at $\mathrm{p}<0.001$

Figure 1. Year-over-Year changes in percent Advanced and Proficient Student Performance with the Integrated Program

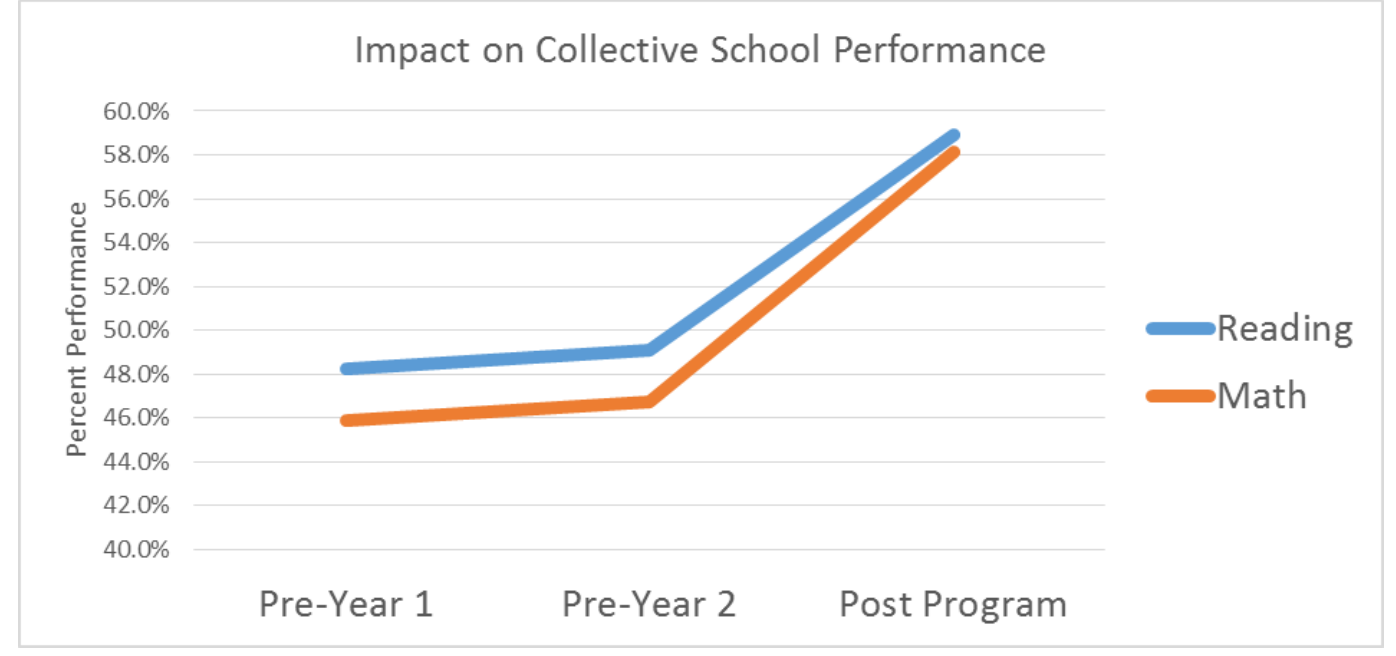

In contrast, results for the Post Program year revealed highly favorable gains and significant Program impacts from the Pre-Year 2 baselines for Reading and Math, alike, far outpacing the baseline rates for Year 1 to Year 2 (see Table 2 and Figure 1). All told, the year-over-year impacts on student performance attributable to the Program were $19.96 \%$ and $24.41 \%$ for Reading and Math, respectively. 
Restated, those figures indicated that for Reading, for example, one student of every five who was previously performing at lower classification levels experienced a promotion to Proficient or Advanced performance levels beyond the $1.9 \%$ change at baseline $(\mathrm{p}<0.001)$. Math showed even more dramatic impact, wherein nearly one student of every four students previously performing at lower classification levels now performed higher and at a Proficient or Advanced performance levels versus the former baseline change of $1.7 \%(\mathrm{p}<0.001)$.

\section{IMPACT ON ECONOMICALLY DISADVANTAGED STUDENTS}

Additional analyses were conducted for the additional 14 schools classified as Title 1 for evaluating the PDL Program impact on the population best representing economically disadvantaged (c.f. Aud, et al, 2010; Lee, 2002; Shaha, Glassett \& Copas, 2015b). To best represent the impact of the PDL Program's impact for Title 1 schools, the amount of performance gap between Title 1 and non-Title 1 schools was quantified and analyzed beyond year-overyear change alone (c.f. Aud, et al, 2010; Lee, 2002). Non-Title 1 schools were selected from the 52 in the previous data reflecting best possible matches geographically.

The gap in percentage of student performing at Proficient and Advanced levels was not significantly reduced between the two pre-PDL Program years. While a slight reduction in the gap was achieved for the 14 Title 1 schools collectively, the gap's closing was very nearly $0.0 \%$ for both Reading and Math (see Table 2). However, once the PDL Program was in place - both online, on-demand PDL and the participative PDL Seminar - the performance gap fell substantially and significantly (see Table 3 and Figure 2). For Reading, the gap for percentage of students classified as Proficient and Advanced, for Title 1 versus non-Title 1 schools, was reduced by more the $35 \%$ for Reading from the last Pre-Year baseline to the end of the first Post Program year $(\mathrm{p}<0.001)$ : The gap experienced a net reduction of $8.3 \%$ for the percentage of students at Proficient and Advanced levels of achievement. For Math the impact was even greater, as the Proficient and Advanced gap fell by more the $40 \%$ in the first Post Program year $(\mathrm{p}<0.001)$, a net gap reduction of over $11 \%$ for the percentage of students at Proficient and Advanced levels of achievement.

Table 3. Performance Gap for Title 1 versus Non-Title 1 Schools in Percent of Students Proficient and Advanced

\begin{tabular}{l|c|c|c|c|c|c|c}
\hline & \multicolumn{3}{|c|}{ Baselines } & \multicolumn{3}{c}{ Program Impacts } \\
\hline Pre-Year 1 & Pre-Year 2 & $\begin{array}{c}\text { Year-over-Year } \\
\text { Gap Change }\end{array}$ & $\begin{array}{c}\text { Normal Change } \\
\text { Rate }\end{array}$ & Post Program & $\begin{array}{c}\text { Year-over-Year } \\
\text { Gap Change }\end{array}$ & $\begin{array}{c}\text { Program-enabled } \\
\text { Change Rate }\end{array}$ \\
\hline Reading & $23.8 \%$ & $23.6 \%$ & $-0.2 \%+$ & $-0.8 \%+$ & $15.3 \%$ & $-8.3 \% * *$ & $-35.17 \% * *$ \\
\hline Math & $27.7 \%$ & $27.6 \%$ & $-0.1 \%+$ & $-0.4 \%+$ & $16.3 \%$ & $-11.3 \% * *$ & $-40.94 \% * *$ \\
\hline
\end{tabular}

† - Not statistically significant

** - Statistically significant at $\mathrm{p}<0.001$

Figure 2. Falling gap for percent students Proficient and Advanced for Title 1 versus non-Title 1 schools

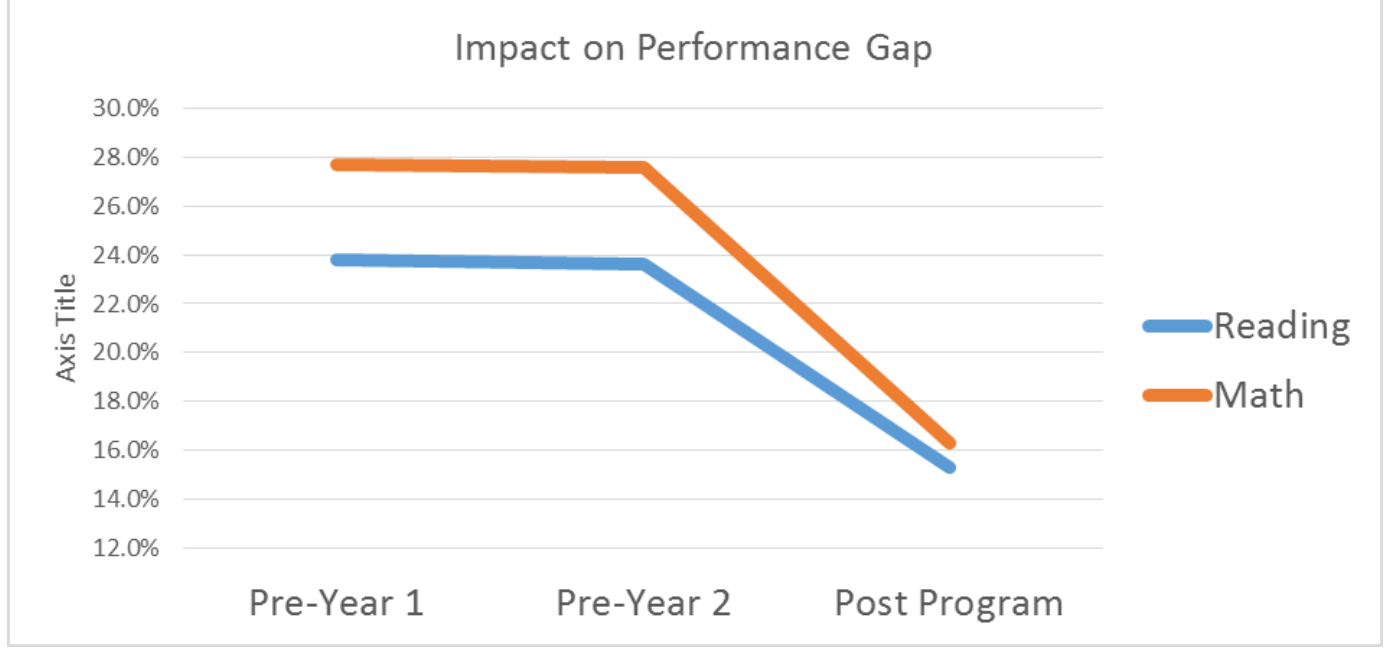




\section{INTERPRETATIONS AND CONCLUSIONS}

Results indicate that educational leaders and their organizations would substantively benefit from the execution of such integrated approaches to both PDL Seminars and online, on-demand PDL for active educators. The combination of online, on-demand professional development and learning with a coordinated, integrated PDL Seminar resulted in impacts on student performance significantly more than prior to the implementation, or to what could be expected for either approach separately.

Specifically, for example, the nearly 20\% improvement in Proficient and Advanced student-count achieved through integrated approach for Reading performance represents student gains $10.3 \%$ higher than the $18.1 \%$ year-over-year growth shown in analogous studies of online, on-demand PDL approach alone (c.f. Shaha \& Ellsworth, 2013; Shaha, Glassett \& Copas, 2015a ). For math, the over-24\% gain in Proficient-Advanced student-count was more than 29\% higher than the $18.9 \%$ advantage documented for the studies of the online PDL alone.

Data further showed that the effect was equally remarkable for Title 1 schools with student populations often described as economically disadvantaged. Closing performance gaps represents evidence of the long-sought capability to establish a more equally impactful approach to education, regardless of the populations of students being served.

A host of recommendations emerge from these analyses, some from the data and some from the common-sense experiences of careers as educators. First, it is strongly recommended that educators heed evidence and pursue the most effective PDL approaches proven with research and data. From previous studies it is clear that, in order to maximize their impact on student performance, educators should undertake well-initiated and actively pursued online, on-demand PDL for their active teachers and educators. Now an additional enhancement has been defined and assessed: it is substantiated that incorporation of an integrated, aligned PDL Seminar in concert with the online, On-demand PDL should enable even more substantively favorable impacts for teachers, as measured in student performance.

Second, it is recommended that decision-makers be conservative in their anticipations and expectations, and in their goals and promises. Analyses of averages, as found in this and most rigorous studies, describe general patterns that mask both the extraordinarily better than average in the sample, as well as the unfortunately lower-than-average within the same data. Investing in PDL approaches that benefit from the integration of both seminars and Internetdelivered PDL is a no-brainer, as the saying goes, and should be quickly and aggressively pursued. However, setting goals that reflect percentages of change rather than massive gross changes in student performance will generally lead to more realistic expectations and more celebrated accomplishments thereafter. It is unclear whether all schools in all districts and states, and all teacher cadres and student populations, can or will achieve the levels of accomplishment found in these data. That said, however, there is no reason to anticipate lesser impacts.

\section{AUTHOR BIOGRPAHIES}

Steven H. Shaha, Ph.D., DBA, Professor, University of Utah, Center for Policy \& Public Administration, Principal Outcomes Consultant, Allscripts, Independent Evaluator. Professor Shaha has 35+ years' in program evaluation and outcomes research with 100+ educational program evaluations within 200+ organizations and governments in 11 countries, four continents, public, private, for-profit and not-for-profit. Steve holds MA, Med, and PhDs in Research Methods \& Applied Statistics and in Business Administration (DBA). He has 220+ presentations, $180+$ journal publications, three books. He lectured at 20 universities, including Harvard, Cambridge (UK), Columbia, Cornell, UCLA and Zayed University (UAE). He presented twice to the United Nations in 2015. He also has served 50+ non-educational organizations include Disney, Ritz-Carlton, RAND, Coca-Cola, TimeWarner, NewLine Cinema. Email: steve.shaha@allscripts.com

Kelly Glassett, Ph.D., currently serves as the content specialist for School Improvement. Prior to his current position he was an Associate Professor and Director of Teacher Education at SIUC. The focus of his scholarship and research activity has been directed towards teacher preparation, literacy and learning in $21^{\text {st }}$ century classrooms, and technology integration in educational environments. He has worked as a classroom teacher in K-12 settings for over 
fifteen years and taught at the collegiate level for over eight years. He has authored or coauthored over 35 peerreviewed articles and over 70 conference presentations on his research.

Email: Kelly.glassett@schoolimprovement.com

Aimee Copas, Ph.D., is the Executive Director for the North Dakota (USA) Council of Educational Leaders; the organization that provides the strongest unifying voice representing/supporting educational leaders in pursuit of quality education for all students. Aimee is also an adjunct professor for the University of Mary and NDSU. Aimee was the Associate Vice Chancellor for Academic Affairs/Director of Research for the North Dakota University System, a college dean, principal, English teacher, basketball coach, \& National Trainer for a pharmaceutical company. Aimee acquired her undergraduate degree from the University of Mary, her MS at Northern State University, \& Doctorate from the University of South Dakota.

Lisa Huddleston is the principal of Livingston County Middle School in Burna, Kentucky. Lisa has also been an adjunct professor for the University of Kentucky's Hopkinsville Community and Technical College System and a high school math teacher. Lisa acquired her undergraduate degree from the University of Kentucky, her MA at Austin Peay State University, \& her Rank I in Administration and Supervision from Murray State University.

\section{REFERENCES}

Abdal-Haqq, I. (1996). Making Time for Teacher Professional Development. ERIC Digest.

Aud, S.; Fox, M.A. \& KewalRamani, A (2010). Status and Trends in the Education of Racial and Ethnic Groups. National Center for Education Statistics, U.S. Department of Education, 2010-015.

Avalos, B. (2011). Teacher professional development in Teaching and Teacher Education over ten years. Teaching and teacher education, 27(1), 10-20.

Borko, H. (2004). Professional development and teacher learning: Mapping the terrain. Educational researcher, 33(8), 3-15.

Borko, H., Jacobs, J., Eiteljorg, E., \& Pittman, M. E. (2008). Video as a tool for fostering productive discussions in mathematics professional development. Teaching and teacher education, 24(2), 417-436.

Boyle, B., While, D., \& Boyle, T. (2004). A longitudinal study of teacher change: what makes professional development effective? Curriculum Journal, 15(1), 45-68.

Cook \& Campbell, 197

Dede, C. (2006). Online Professional Development for Teachers-Emerging Models. Harvard Education Press.

Garet, M. S., Porter, A. C., Desimone, L., Birman, B. F., \& Yoon, K. S. (2001). What makes professional development effective? Results from a national sample of teachers. American educational research journal, 38(4), 915-945.

Koehler, M. J., Mishra, P., \& Yahya, K. (2007). Tracing the development of teacher knowledge in a design seminar: Integrating content, pedagogy and technology. Computers \& Education, 49(3), 740-762.

Koc, Y., Peker, D., \& Osmanoglu, A. (2009). Supporting teacher professional development through online video case study discussions: An assemblage of preservice and inservice teachers and the case teacher. Teaching and Teacher Education, 25(8), 1158-1168.

Lee, J. (2002). Racial and ethnic achievement gap trends: Reversing the progress toward equity. Educational researcher, 31(1), 3-12.

Schlager, M. S., \& Fusco, J. (2003). Teacher professional development, technology, and communities of practice: Are we putting the cart before the horse? The Information Society, 19(3), 203-220.

Schrum, L. (1995). Educators and the Internet: A case study of professional development. Computers \& Education, 24(3), 221228.

Shaha SH, Ellsworth H (2013). Multi-State, Quasi-experimental Study of the Impact of On-demand Professional Development on Students Performance. International Journal of Evaluation and Research in Education (IJERE). Vol.2, No. 4.

Shaha SH, Ellsworth H (2014a). Predictors of Success for Professional Development: Linking Student Achievement to School and Educator Successes through On-Demand, Online Professional Learning. Journal of Instructional Psychology (JIP), Vol. 40, No. 1.

Shaha SH, Ellsworth H (2014b). Impact of Online Delivered Professional Development on Educators in Title I Schools. Society for Information Technology and Teacher Education International Conference 2014, Jacksonville, Florida, March 17-21, 2014.

Shaha SH, Glassett KF, Copas A (2015a). Sustaining Student Gains from Online On-Demand Professional Development. Journal of International Education Research. Volume 11, Number 3.

Shaha SH, Glassett KF, Copas A (2015b). The Impact of Teacher Observations with Coordinated Professional Development on Student Performance: A 27-State Program Evaluation. Journal of College Teaching \& Learning. Vol 12 (1).

Shaha SH, Glassett K, Ellsworth H (2015). Long-term Impact of On-demand Professional Development on Student Performance: A Longitudinal Multi-State Study. Journal of International Education Research. Vol 11(1). 
Shaha SH, Glassett KF, Copas A, Ellsworth, H (2015). The Impact of Online, On-Demand Professional Development on Educators and their Students in Title I Schools: Quasi-Experimental Study. (in review).

Villegas-Reimers, E. (2003). Teacher professional development: an international review of the literature. Paris: International Institute for Educational Planning.

Wayne, A. J., Yoon, K. S., Zhu, P., Cronen, S., \& Garet, M. S. (2008). Experimenting with teacher professional development: Motives and methods. Educational researcher, 37(8), 469-479.

Wilson, S. M., \& Berne, J. (1999). Teacher learning and the acquisition of professional knowledge: An examination of research on contemporary professional development. Review of research in education, 173-209.

Zeichner, K. M. (2003). Teacher research as professional development for P-12 educators in the USA [1]. Educational action research, 11(2), 301-326.

Zhang, M., Lundeberg, M., Koehler, M. J., \& Eberhardt, J. (2011). Understanding affordances and challenges of three types of video for teacher professional development. Teaching and Teacher Education, 27(2), 454-462. 